\title{
Aprendizagem e Desenvolvimento: Um Estudo sobre recomendações alimentares para a criança na Educação Infantil
}

\author{
Sabrina Gomes Bezerra Freire ${ }^{1}$; Maria do Socorro Farias Pinheiro ${ }^{2}$; \\ Maria Patrícia de Alencar ${ }^{3}$; Maria do Socorro Cecílio Sobral ${ }^{4}$
}

\begin{abstract}
Resumo: O papel da alimentação saudável na escola é de suma importância, pois a criança passa uma boa parte do seu tempo na escola ou creche. A criança vai aprendendo a ter novos hábitos de se alimentar, através da observação. Com a modernidade e praticidade de lanches mais rápidos os pais estão oferecendo aos filhos para que eles levem a escola, sabendo que esses alimentos nem sempre trazem nutrientes e nem benefícios a saúde dos filhos. Nesse estudo o objetivo foi de analisar a qualidade dos alimentos oferecidos na escola de educação infantil. A metodologia utilizada foi a abordagem qualitativa e estudo exploratório com a técnica do questionário semi-estruturado sobre a alimentação saudável para crianças da educação infantil. A pesquisa foi realizada em escolas do município de Salgueiro-PE. Através das informações colhidas, percebeu que os alunos não consomem alimentos saudáveis, e sim, dão preferência a lanches industrializados. Neste sentido, acredita-se que a inclusão de alimentos saudáveis nas escolas de educação infantil permite que essas crianças tenham outra forma de olhar para os alimentos saudáveis, favorecendo grandemente para o processo de desenvolvimento dos alunos. É necessário que os pais e professores incentivem os alunos a ingerirem alimentos mais saudáveis, trabalhar com atividades lúdicas que utilizam os alimentos saudáveis é uma forma de incentivar os alunos a mudar o seu modo de se alimentar. A contribuição da pesquisa é um alerta para o fato das crianças não estarem se alimentando de maneira adequada, para que possam ter um melhor desenvolvimento dos aspectos motores, psicossociais e cognitivos.
\end{abstract}

Palavras-Chave: Alimentação Saudável, Crianças, Educação Infantil.

\section{Learning and Development: A Study on Food Recommendations for Children in Early Childhood Education}

\begin{abstract}
The role of healthy eating in school is very importance because the child spends a good deal of his time in school or day care. The child learns to have new eating habits through observation. With the modernity and practicality of faster snacks parents are offering their children to take to school, knowing that these foods do not always bring nutrients or health benefits to their children. In this study the objective was to analyze the quality of food offered at the kindergarten. The methodology used was the qualitative approach and exploratory study with the semi-structured questionnaire technique on healthy eating for children in early childhood education. The research was carried out in schools of the municipality of Salgueiro-PE. Through the information collected, he realized that students do not consume healthy food, but rather give preference to industrialized snacks. In this sense, it is believed that the inclusion of healthy foods in nursery schools allows these children to
\end{abstract}

\footnotetext{
${ }^{1}$ Faculdade de Ciências Humanas do Sertão Central (FACHUSC). Contato: sabrinaformal@ hotmail.com;

${ }^{2}$ Licenciatura em ciências com habilitação em biologia pela URCA. Licenciatura em Pedagogia pela UNIFATEC FATEC - Faculdade de Ciências administrativas e de tecnologia - Estado de Rondônia. Especialista em Docência do ensino Superior e gestão escolar pela UNIFATEC FATEC. Especialista em Docência do ensino superior pela faculdade KURIUS. Coordenadora Pedagógica da educação infantil do município de Juazeiro do Norte. Coordenadora do curso de Pedagogia do Instituto IESEM e Professora do curso de pedagogia. Contato: mariadosocorrofariaspinheiro@gmail.com;

${ }^{3}$ Graduação em Administração pelo Centro Universitário Dr. Leão Sampaio (2017). Durante a graduação ocupou a função de monitora das disciplinas de matemática básica, matemática financeira e Trabalho de Conclusão de Curso com bolsa de fomento. Participou da V Olimpíada de Matemática Financeira na Unileão onde tirou o $1^{\circ}$ lugar. Foi membro da Diretoria Executiva da Empresa Junior Avance Consultoria Assessoria e Treinamento do Centro Universitário Dr. Leão Sampaio - UNILEÃO. Contato: patriciaalencar133@ gmail.com;

${ }^{4}$ Mestrado em Educação em Ciências pela Fundação de Apoio à Universidade Federal do Rio Grande do Sul, Brasil. Docente e Orientadora na Faculdade de Ciências Humanas do Sertão Central (FACHUSC). Contato: socorrosobral@ bol.com.br.
} 
have another way of looking at healthy foods, favoring greatly the development process of the students. Parents and teachers need to encourage students to eat healthier foods, work with playful activities that use healthy foods is a way to encourage students to change their ways of eating. The contribution of the research is an alert to the fact that children are not feeding properly, so that they can have a better development of motor, psychosocial and cognitive aspects.

Keywords: Healthy Eating, Children, Early Childhood Education.

\section{Introdução}

O presente estudo tem como justificativa a necessidade das crianças terem uma boa alimentação e um melhor desenvolvimento no ensino aprendizagem no âmbito escolar e de acordo com a observação e experiência docente essa necessidade ainda não está suprida. De acordo com Dartora, et al, (2006, p. 2), A nutrição é um fator essencial na manutenção da saúde. Através de refeições balanceadas constitui um dos recursos utilizados pela medicina preventiva, alicerçados a outros para determinar uma vida saudável e duradoura. Sabe-se da importância da nutrição em todas as fases da vida e em especial para o bom rendimento escolar do estudante a partir da infância. Essa pesquisa tem como objetivo analisar a qualidade dos alimentos oferecidos na escola de educação infantil. O campo do referido estudo foi escola pública e privada do município de Salgueiro, localizado na mesorregião do Sertão Central do Estado de Pernambuco. A questão da pesquisa se deu por observar que mesmo a escola tendo boa alimentação, é comum os alunos ainda levarem lanches que não tem nutrientes que possam promover melhoria no rendimento do escolar.

A metodologia utilizada foi um questionário estudo exploratório qualitativo sobre a alimentação saudável para crianças da educação infantil. Neste sentido levantaram-se também informações sobre os fatores considerados mais importantes nas necessidades nutricionais das crianças, na pesquisa de campo utilizou o questionário com as seguintes perguntas. Como é feita a alimentação dos alunos na escola, e que tipos de alimentos saudáveis são oferecidos na escola? As crianças podem levar lanches para a escola? E que tipos de lanches eles levam? A escola tem um acompanhamento com o nutricionista?

Desse modo a contribuição da pesquisa como um alerta cada vez maior, para o fator nutricional a ser tratado com mais atenção em todas as instituições da educação infantil devido sua grande importância no processo ensino aprendizagem a partir dos primeiros passos dos estudantes com vistas ao melhor desenvolvimento dos aspectos motores, psicossociais e 
cognitivos. Contribuir também na conscientização dos pais, em não trocarem os alimentos saudáveis pelos lanches industrializados, fazendo a criança passar por problemas de saúde, ocasionados por esses lanches que não tem nutrientes, fonte de vitaminas, ferro, cálcio etc.

\section{As principais características da alimentação das crianças da Educação Infantil}

Esta fase é caracterizada pelo amadurecimento da habilidade motora, da linguagem e das habilidades sociais relacionadas à alimentação, sendo este um grupo vulnerável que depende dos pais ou responsáveis para receber alimentação adequada. A fase pré-escolar envolve comportamentos e atitudes que persistirão no futuro, podendo determinar uma vida saudável, à medida que um conjunto de ações que envolvem o ambiente familiar e escolar.

\footnotetext{
"A alimentação escolar tem característica de assistência nutricional, desde que ofereça alimentos adequados em quantidade e qualidade, para satisfazer ás necessidades nutricionais do escolar, no período do dia em que permanece na escola. (mas também,) por ser servida na escola, adquire característica de ferramenta educativa, que pode e deve ser utilizada para os fins maiores da educação, (...) habilitando o aluno a intervir na própria realidade" Conselho federal de nutricionistas (1995, apud COSTA, 2001, p. 227)
}

Esta resolução do Conselho Federal atribui total importância ao fator no âmbito escolar como ferramenta educativa e como satisfatória as necessidades do escolar se oferecida com alimentos adequados em quantidade e qualidade, segundo (PHILIPPI, 2003)

Nos primeiros anos de vida, é essencial para o crescimento e desenvolvimento da criança uma alimentação qualitativa e quantitativamente adequada, pois ela proporciona ao organismo a energia e os nutrientes necessários para o bom desempenho de suas funções e para a manutenção de um bom estado de saúde.

Para que a criança tenha um bom desenvolvimento os pais têm quer ser os primeiros a se responsabilizar pelo lanches que as crianças estão levando para a escola e assim evitando que mais na frente seus filhos fiquem doentes. Uma boa alimentação enquanto criança ou até mesmo para um adulto é de suma relevância, pois proporciona uma vida saudável e com, mas energia. 


\title{
A Importância dos hábitos alimentares saudáveis na Educação Infantil.
}

Os hábitos alimentares acontecem desde o surgimento do mundo, o que modifica esses padrões são as culturas. Cada cultura ou lugar tem o seu modo de se alimentar, o alimento é apresentado a crianças desde o seu nascimento com o leite materno, a partir daí a família é a responsável por oferecer e influenciar a criança a consumir alimentos saudáveis, porém a infância é caracterizada por uma intensa vulnerabilidade biológica. $\mathrm{O}$ processo alimentar tem uma série de implicações emocionais e psicológicas:

As experiências alimentares no começo de vida têm importantes desdobramentos na formação dos traços da personalidade, na vida adulta; mas antes de chegar à fase adulta é um longo caminho e é muito cedo que a população infantil se vê sujeita a diversos agravos nutricionais, como diabetes e hipertensão arterial e dislipidemias.

Tendo em vista os agravos acima, bem como as experiências alimentares na infância, a escola é fundamental para determinação dos hábitos, uma vez que o aluno permanece no local em período parcial ou integral, interagindo com educadores, manipuladores de alimentos e outras crianças que irão gerar influencias em seu estilo de vida, nesse aspecto afirma pesquisador:

\begin{abstract}
A criança tem seu comportamento alimentar moldado pela sociedade na qual está inserida. E, durante essa etapa do ciclo de vida em que os hábitos alimentares são formados, os alimentos ingeridos são escolhidos pela observação e educação, processos nos quais a família e a escola exercem papel fundamental (MOTA et al., 2013)
\end{abstract}

Segundo o artigo 208 da constituição federal de 1998, a alimentação para alunos da rede pública passou a ser considerada um direito garantido por meio de um programa social: O Programa Nacional de Alimentação Escolar - PNAE. Este tem como principais objetivos a contribuição para o crescimento e desenvolvimento da população infantil, o rendimento escolar e a promoção de hábitos alimentares saudáveis. Para alcançá-los, o PNAE busca introduzir refeições que ofereçam as necessidades nutricionais do público infantil em todo o período letivo e realizar intervenções visando a educação alimentar e nutricional através da mudança dos hábitos alimentares.

Mudanças nos hábitos alimentares têm sido observadas em diversos países. Essas mudanças estão associadas, entre outros fatores, com o sistema de desenvolvimento 
da distribuição e da produção de gêneros alimentícios e com o fenômeno da urbanização, influenciando o estilo de vida e a saúde da população (MONDINI \& MONTEIRO, 1994; OLIVEIRA, 1997).

Com base no que diz o autor, o estilo de vida das pessoas é que estão mudando os hábitos alimentares. Hoje em dia estão sendo utilizados alimentos industrializados e deixando de lado os alimentos saudáveis, a crianças começa a mudar seus hábitos alimentares quando passam a freqüentar outros lugares de socialização (parques, clubes, escolas etc.). Nesses lugares a criança vê outros alimentos e conseqüentemente vai querer comer, e isso acontece muito no âmbito escolar, onde sempre existe a troca de lanches e assim a criança vai deixando seus hábitos alimentares saudáveis de lado e comendo alimentos industrializados.

\section{Com a má alimentação podemos desencadear varias doenças enquanto criança.}

Como ainda existem desigualdades sociais no nosso país, e conseqüentemente provoca nas pessoas uma modificação no seu modo de se alimentar e gerando assim na população brasileira o aumento das doenças crônicas não transmissíveis, com ênfase no excesso de peso e obesidade, assumindo proporções alarmantes, especialmente entre as crianças. Diversos agravos nutricionais, além de situações de falta de apetite às refeições básicas e/ou alimentos. Isto decorre de vários fatores que podem estar relacionados a uma maior seletividade em relação aos alimentos, fácil acesso a guloseimas, além da incidência de infecções e verminoses que podem diminuir o apetite. Alimentação saudável é aquela na qual se ingerem alimentos de forma equilibrada para que adultos mantenham seu peso ideal e crianças desenvolvam-se adequadamente tanto intelectual quanto fisicamente. KRAUSE (2013, apud XEREZ, 2016, p. 14). Referente ao conceito de alimentação saudável para que ampliar a compreensão do leitor sobre valor nutricional foi encontrado idéias bem significativas a segui:

\footnotetext{
A espécie humana necessita de dieta variada para garantir a nutrição adequada, pois os nutrientes estão distribuídos em quantidades diferentes nos alimentos. Estes são classificados em grupos, de acordo com o nutriente que se apresenta em maior quantidade. Os que pertencem ao mesmo grupo podem ser fontes de diferentes nutrientes. Por exemplo, grupo das frutas: o mamão é fonte de vitamina A e o caju é fonte de vitamina C. Então, além de consumir alimentos de todos os grupos, é importante a variedade década grupo (BRASIL, 2002a, 2002b).
} 
A falta dos nutrientes adequados a cada faixa etária pode ocasionar doenças nas crianças, afetando assim no rendimento escolar, por isso é de suma importância que as crianças se alimentem de frutas, verduras, legumes, por conter fontes de vitaminas (A, B, C e ácido fólico) entre outros, minerais como (cálcio, ferro, zinco, fósforo e magnésio) entre outros e fibra. Também é importante ressaltar que a criança tem que ter o costume de lavar as mãos sempre antes de comer, evitando assim repassar bactérias e doenças para o seu organismo.

\section{Tipos de Doenças causadas pela má alimentação e algumas consequências.}

Anemia ferropriva - é uma das doenças mais comuns em crianças. O ferro é um nutriente essencial para a vida. E alimentos pobres de ferro é o maior causador de anemia. Os principais sintomas são: cansaço falta de apetite, palidez apatia (criança muito parada).

Desnutrição - a desnutrição provoca grandes conseqüências para o desenvolvimento da criança. Os sintomas são: perda de peso que prejudica o crescimento normal da criança para toda a vida, afeta o desenvolvimento da aprendizagem e retardo no cérebro. A desnutrição e a causa mais freqüente de morte em crianças de até cinco anos de idade.

\footnotetext{
A desnutrição pode culminar na mortalidade, principalmente em crianças, se não for tratada a tempo. Além disso, ela ocasiona outros problemas, como: “[...] crescimento e desenvolvimento deficiente, maior vulnerabilidade a doenças infecciosas, comprometimento de funções reprodutivas e redução da capacidade de trabalho". (MONDINI e MONTEIRO, 1998 apud LIMA, 2008, p. 19)
}

Sobrepeso e Obesidade - tanto o sobrepeso como a obesidade é causada pelo desequilíbrio de quantidade de calorias consumidas e a quantidade de calorias gasta pelo organismo para a realização de atividades exercida no dia. $\mathrm{O}$ excesso de peso na infância pode levar o aumento dos níveis de gordura no sangue problemas nas articulações, no fígado, nos músculos e diabete que é uma doença causada pela ausência de insulina, com a falta de insulina o açúcar se acumula no sangue causando a diabete, que pode prejudicar alguns órgãos como: rins, coração, olhos e pés.

Hipertensão arterial - a hipertensão é conhecida como pressão alta, é uma doença crônica e ela é causadora de complicações cardiovascular e renal entre outras; como a 
dislipidemia que é a presença de gordura no sangue, gordura essa conhecida como colesterol. O colesterol é um tipo de gordura produzida no fígado e tem o bom e o ruim, o bom é ótimo para nosso organismo já o ruim pode se tornar um fator de risco para o desenvolvimento de doenças cardiovasculares.

\section{Metodologia}

O presente é exploratório e qualitativo, sobre aprendizagem, desenvolvimento e alimentação saudável para crianças da educação infantil. Neste sentido levantou-se também informações sobre os fatores considerados mais importantes nas necessidades nutricionais das crianças.

Foi realizado em escola pública e privada no município de salgueiro - PE, localizada no sertão pernambucano. A referida cidade fica á $518 \mathrm{~km}$ da capital Recife-PE. Onde foi aplicado questionário em duas escolas, para analisar os aspectos relacionados à temática. Os dados foram coletados através de um questionário, aplicado com 06 professores. Sendo 03 da Escola pública, que contempla cerca de 260 crianças matriculadas, com faixa etária de três, quatro e cinco anos, e é mantida pelo município, e 03 professores na escola privada que atende 53 crianças na fixa etária de três, quatro e cinco anos do ensino infantil.

\section{Resultados e Discussão}

Participaram do estudo de campo através de questionário com 6 professoras, sendo 3 do ensino público e 3 do particular. O mesmo indagava sobre o tipo de alimentação saudável oferecida pela escola e como está é realizada. Onde a resposta apontava para consumo de sucos, frituras, carboidratos, refrigerantes, biscoitos, doces, bolos, achocolatados, frutas e sem o acompanhamento do nutricionista, porque os alunos trazem esses lanches de casa, isso no caso da escola particular.

Quanto às professoras questionadas da escola pública, estas afirmaram que o cardápio oferecido aos estudantes para consumo era acompanhado pelo nutricionista onde repassam informações para as merendeiras e apresentavam-se com frutas, verduras, legumes, carnes e 
cereais. Mesmo sendo orientados a não levar lanches de casa para a escola cerca de $40 \%$ dos alunos levam refrigerantes, pipocas, doces, suco industrializado, carboidratos em geral. Conforme mostra a tabela abaixo de forma mais detalhada esses resultados.

Tabela 1: Informações coletadas sobre a alimentação saudável na educação infantil.

\begin{tabular}{|c|c|c|}
\hline Perguntas & Escola Pública & Escola Particular \\
\hline $\begin{array}{l}\text { 1. Como é feitas a } \\
\text { alimentação a dos } \\
\text { alunos na escola, e } \\
\text { que tipos de alimentos } \\
\text { saudáveis } \\
\text { oferecidos? }\end{array}$ & $\begin{array}{l}\text { É através do cardápio e } \\
\text { acompanhado } \\
\text { nutricionista, composto de } \\
\text { frutas, verduras e legumes }\end{array}$ & $\begin{array}{ll}\text { A escola disponibiliza } & \text { de } \\
\text { cantinas para as vendas de } \\
\text { lanches, e outros trazem de } \\
\text { casa. }\end{array}$ \\
\hline $\begin{array}{l}\text { 2. As crianças podem } \\
\text { levar lanches para a } \\
\text { escola? E que tipo de } \\
\text { lanches eles levam? }\end{array}$ & $\begin{array}{l}\text { Orientandos a não levar } \\
\text { lanche, embora } \\
\text { aproximadamente } 40 \% \text { dos } \\
\text { alunos levam refrigerantes, } \\
\text { pipocas, doces, suco } \\
\text { industrializados, carboidratos } \\
\text { em geral. }\end{array}$ & $\begin{array}{l}\text { Sim, os alunos trazem esses } \\
\text { lanches de casa, tipos de } \\
\text { lanches: sucos, frituras, } \\
\text { carboidratos, refrigerantes, } \\
\text { biscoitos, doces, bolos, } \\
\text { achocolatados, frutas. }\end{array}$ \\
\hline $\begin{array}{l}\text { 3. A escola tem } \\
\text { acompanhamento com } \\
\text { o nutricionista? }\end{array}$ & Sim & Não \\
\hline
\end{tabular}

Fonte: Dados da pesquisa.

Segundo o questionário podemos ver que as crianças preferem alimentos não saudáveis, e isso é por conta dos novos hábitos alimentares que a família leva, e a criança acaba se acostumando com esses alimentos, causando assim um desequilíbrio no seu corpo, tipo algumas doenças (gripe, infecção, anemia, sobrepeso, diabete etc.). A criança precisa de alimentos ricos em nutriente para ter, mas energia no seu organismo, conseqüentemente essa criança terá um bom desenvolvimento na aprendizagem escolar e no físico.

\section{Considerações Finais}

Através dos estudos realizados nas escolas sobre alimentação saudável pudemos compreender que uma boa alimentação enquanto crianças é fundamental tanto para seu

18 Id on Line Rev. Mult. Psic. V.13, N. 45 SUPLEMENTO 1, p. 11-20, 2019 - ISSN 1981-1179 Edição eletrônica em http://idonline.emnuvens.com.br/id 
crescimento com para o seu desenvolvimento na aprendizagem, se essa alimentação não for de boa qualidade e com nutrientes, a criança pode apresentar problemas de saúde, por isso é necessário que os pais, professores incentivem os alunos a ingerir alimentos mais saudáveis, trabalhar com atividades lúdicas que utilizam os alimentos saudáveis é uma forma de incentivar os alunos a mudar o seu modo de se alimentar.

Neste sentido, acreditamos que as inclusões de alimentos saudáveis nas escolas de educação infantil permitem que essas crianças tenham outra forma de olhar para os alimentos saudáveis favorecendo grandemente para o processo de desenvolvimento dos alunos. Por fim as escolas e os pais devem enfatizar a formação do senso crítico da criança, para que não sejam atraídas pelas propagandas de produtos industrializados com seus desejos de compras e conscientizar a adotar hábitos saudáveis de alimentação incluindo exercícios físicos regulares.

\section{Referências}

BRASIL. Ministério da Saúde. Secretaria de Atenção à Saúde. Departamento de Atenção Básica. Saúde da criança: nutrição infantil: aleitamento materno e alimentação complementar / Ministério da Saúde, Secretaria de Atenção à Saúde, Departamento de Atenção Básica. - Brasília: Editora do Ministério da Saúde, 2009.

COSTA, E. de Q.; RIBEIRO, V. M. B.; RIBEIRO, E. C. de O. Programa de alimentação escolar: espaço de aprendizagem e produção de conhecimento. Rev. Nutr., Campinas, 14(3): 225-229, $\quad$ set./dez., $2001 . \quad$ Disponível em: <http://www.scielo.br/pdf/rn/v14n3/7789.pdf> Acesso em: 25 de setembro de 2018.

DARTORA, N., VALDUGA, A. T., VENQUIARUTO, L. Alimentos e saúde: uma questão de educação. Vivências, Erechim. V. 01, ano 2, nº 3 p.201-212 - Outubro de 2006.

MONDINI, L. \& MONTEIRO, C. A. Mudanças no padrão de alimentação da população urbana brasileira (1962-1988). Rev. Saúde Pública [online]. 1994, vol.28, n.6, pp.433-439. ISSN 0034-8910. Disponível em: <http://www.scielo.br/scielo.php?pid=S0034$89101994000600007 \&$ script=sci_abstract\&tlng=pt $>$ Acesso em 03 de setembro de 2018.

MOTA, H. C.; MASTROENI, S. S. B. S.; MASTROENI, M. F. Consumo da refeição escolar na rede pública municipal de ensino. Revista Brasileira de Estudos Pedagógicos, Brasília, DF, v. 94, n. 236, p. 168-184, jan./abr. 2013.

PHILIPPI, S. T.; CRUZ, A. T. R.; COLUCCI, A. C. A. Pirâmide alimentar para crianças de 2 a 3 anos. Rev. Nutr. vol.16 no.1 Campinas Jan./Mar. 2003 Print version ISSN 14155273On-line version ISSN 1678-9865.

Disponível

em: 
<http://www.scielo.br/scielo.php?script=sci_arttext\&pid=S1415-52732003000100002>

Acesso em: 25 de setembro de 2018.

SOUZA, E. R. de. Alimentação saudável na infância. Monografia de especialização, Medianeira, 2014.

Disponível

em:

<http://repositorio.roca.utfpr.edu.br/jspui/bitstream/1/4785/1/MD_ENSCIE_IV_2014_35.pdf

$>$ Acesso em 28 de setembro de 2018.

XEREZ, N. de P. F. Cardápio e qualidade: composição nutricional na alimentação escolar. / Nayana de Paiva Fontenelle Xerez. - Ceuma Universidade, São Luís, 2016.

\section{Como citar este artigo (Formato ABNT):}

FREIRE, Sabrina Gomes Bezerra; PINHEIRO, Maria do Socorro Farias; ALENCAR, Maria Patrícia de; SOBRAL, Maria do Socorro Cecílio. Aprendizagem e Desenvolvimento: Um Estudo sobre recomendações alimentares para a criança na Educação Infantil. Id on Line Rev.Mult. Psic., 2019, vol.13, n.45 SUPLEMENTO 1, p. 11-20. ISSN: 1981-1179.

Recebido: 13/01/2019

Aceito 16/05/2019 